\title{
Sensitivity of simulated South America climate to the land surface schemes in RegCM4
}

\author{
Marta Llopart ${ }^{1,2}$ (D) $\cdot$ Rosmeri P. da Rocha $^{3} \cdot$ Michelle Reboita $^{4} \cdot$ Santiago Cuadra $^{5}$
}

Received: 8 August 2016 / Accepted: 25 January 2017 / Published online: 23 February 2017

(C) Springer-Verlag Berlin Heidelberg 2017

\begin{abstract}
This work evaluates the impact of two land surface parameterizations on the simulated climate and its variability over South America (SA). Two numerical experiments using RegCM4 coupled with the Biosphere-Atmosphere Transfer Scheme (RegBATS) and the Community Land Model version 3.5 (RegCLM) land surface schemes are compared. For the period 1979-2008, RegCM4 simulations used $50 \mathrm{~km}$ horizontal grid spacing and the ERAInterim reanalysis as initial and boundary conditions. For the period studied, both simulations represent the main observed spatial patterns of rainfall, air temperature and low level circulation over SA. However, with regard to the precipitation intensity, RegCLM values are closer to the observations than RegBATS (it is wetter in general) over most of SA. RegCLM also produces smaller biases for air temperature. Over the Amazon basin, the amplitudes of the annual cycles of the soil moisture, evapotranspiration and sensible heat flux are higher in RegBATS than in RegCLM. This indicates that RegBATS provides large amounts of water vapor to the atmosphere and has more available energy to increase the boundary layer thickness and cause it to reach the level of free convection (higher sensible heat
\end{abstract}

Marta Llopart

marta@fc.unesp.br

1 Departamento de Física, Universidade Estadual Paulista (UNESP), Bauru, SP, Brazil

2 Centro de Meteorologia de Bauru (IPMet), Bauru, SP, Brazil

3 Departamento de Ciências Atmosféricas, Universidade de São Paulo (USP), São Paulo, SP, Brazil

4 Natural Resources Institute, Federal University of Itajubá, Itajubá, MG, Brazil

5 Brazilian Agricultural Research Corporation-EMBRAPA, Campinas, SP, Brazil flux values) resulting in higher precipitation rates and a large wet bias. RegCLM is closer to the observations than RegBATS, presenting smaller wet and warm biases over the Amazon basin. On an interannual scale, the magnitudes of the anomalies of the precipitation and air temperature simulated by RegCLM are closer to the observations. In general, RegBATS simulates higher magnitude for the interannual variability signal.

Keywords RegCM4 - BATS - CLM3.5 - CORDEX · Amazon basin $\cdot$ Interannual variability

\section{Introduction}

Numerical experiments with General Circulation Models (GCMs) and Regional Climate Models (RCMs) have shown a large sensitivity of the atmospheric circulation to surface-atmosphere interactions, owing to the fact that there is a large and diverse ecosystem exchanging mass, momentum and heat with the atmosphere (Sellers et al. 1989, 1997; Misra et al. 2002; Steiner et al. 2005, 2009; Silva et al. 2015). For example, energy and mass fluxes between the surface and the atmosphere are sensitive to the surface albedo, soil moisture, the roughness, and other vegetation and soil characteristics operating on different time scales (Sellers et al. 1996a).

One of the major uncertainties in the climate simulations is the parameterization used to simulate the physics processes at the land-atmosphere interface (Sellers et al. 1997; Misra et al. 2002; Stocker et al. 2013; Koster et al. 2004; Seneviratne et al. 2006). Climate models require the calculation of energy, water, and momentum fluxes across the land-atmosphere interface. A poor representation of this interaction may affect climate variables such as near-surface 
temperature, precipitation, and the vertical distribution of atmospheric water vapor and clouds (Misra et al. 2002; Steiner et al. 2005, 2009) and it impacts the reliability of climate predictions. For example, the global land-atmosphere coupling experiment (GLACE2) showed the role of different soil initializations in improving the predictability of near-surface air temperature (Koster et al. 2010, 2011).

Over different regions of the globe, studies have evaluated the influence on climate simulations associated with the improvement of the representation of surface processes in RCMs. Over eastern Asia, Steiner et al. (2005) compared the performance of two surface parameterizations, the Community Land Model (CLM3; Oleson et al. 2008) and BATS (Biosphere-Atmosphere Transfer Scheme; Dickinson et al. 1993), coupled to the RegCM. For air temperature, the CLM simulated higher temperatures in winter, which reduced the cold bias obtained with BATS. For precipitation, the experiment using the CLM provided lower rainfall rates than BATS, mainly due to higher runoff in CLM and the resulting lower water infiltration into the soil. Steiner et al. (2005) showed that soil moisture simulated by CLM is more realistic than that of BATS. Overall, coupling RegCM with CLM provided a hydrological cycle and energy balance closer to the observations over the East Asia region. A similar analysis using RegCM coupled to CLM3.0 and BATS over western Africa was obtained by Steiner et al. (2009), showing high sensitivity of the rainfall associated with the monsoon system to the choice of surface scheme. CLM3.0 provided a large improvement in the representation of the rainfall cycle associated with the monsoon and also in the representation of the interannual variability of precipitation.

For a more realistic simulation of the rainfall climatology over South America (SA), da Rocha et al. (2012) changed some parameters related to the soil moisture in the BATS land surface scheme coupled in RegCM3. These changes reduced the degree of underestimation of tropical rainfall, a recurring error in $\operatorname{Reg} \mathrm{CM} 3$, resulting in a better representation of the South American Monsoon system (SAM; Vera et al. 2006). Using the Rossby Centre RCM, Sörensson and Menéndez (2011) evaluated the timescale of the soil's memory of the atmospheric variability and its impact on the development of the SAM. During the austral summer, these authors found the La Plata and Amazon basins to be hot-spot regions, i.e., areas with strong exchange between surface and atmosphere. Pessacg et al. (2013) analyzed the performance of seven RCMs in the simulation of the energy balance at the surface. Most models overestimate the short wave radiation over the tropical sectors of SA and over the La Plata Basin, and underestimate it over oceanic areas. These errors were attributed to the uncertainties associated with the representation of the surface albedo and cloud cover fraction (Pessacg et al. 2013). Regarding the long-wave radiation, RCMs simulated values close to those of the Global Energy and Water Exchanges (GEWEX-SRB) dataset.

Based on the preceding considerations, the purpose of the present work is to evaluate the sensitivity of the Regional Climate Model version 4 (RegCM4; Giorgi et al. 2012), coupled with two different land surface models (BATS and CLM3.5), in simulating the climate and its interannual variability over the SA CORDEX (Coordinated Regional Downscaling Experiment; Giorgi et al. 2009) domain with focus over the Amazon basin. Methodology and datasets to be used here are described in Sect. 2; the results and conclusions are presented, respectively, in Sects. 3 and 4.

\section{Methodology and data}

\subsection{RegCM4 and design of experiments}

The latest version of the ICTP regional climate model, RegCM4, is used in this study. RegCM4 is an updated version of RegCM3 (Pal et al. 2007) with many upgrades in the model physics. Giorgi et al. (2012) provides a list of the physical options available in RegCM4. One major addition to RegCM4 is the option to use CLM version 3.5 (CLM3.5; Tawfik and Steiner 2011) as an alternative to the BATS (Dickinson et al. 1993) in order to describe land surface processes. A detailed description of the surface schemes can be found in Steiner et al. (2005, 2009). CLM3.5 incorporates substantial upgrades over BATS, but the two have also some components in common, as summarized below.

- BATS This scheme has one vegetation layer, one snow layer, two soil temperature levels and three soil moisture levels with different depths: a surface layer with a thickness of $10 \mathrm{~cm}$, the root zone (with variable thickness according to the vegetation type) and the deep soil (3 to $23 \mathrm{~m}$ in extent). Furthermore, BATS considers 20 land use types, which are described in Elguindi et al. (2004). The hydrologic cycle is calculated by prediction equations of water content in the three layers. Finally, heat fluxes, water vapour and momentum at the surface are calculated on the basis of the drag coefficients obtained fromMonin-Obukov similarity theory applied to the surface layer. The turbulent transports of heat, momentum and humidity in the planetary boundary layer (PBL) are calculated from the product of the vertical gradient of these variables and the vertical turbulent diffusion coefficient (Holtslag et al. 1990). BATS uses a two-layer force-restore model to calculate soil temperature ( Deardorff 1978).

- CLM3.5 This scheme is based on the physical components of three existing land surface schemes: BATS, 
LSM (Land Surface Model; Bonan 1996) and the snow model of Dai and Zeng (1997 - IAP94). It has ten vertical soil levels, up to five snow levels and one vegetation layer coupled with a photosynthesis and stomatal conductance model. For soil temperature and moisture, the model explicitly solves these in its soil layers assuming a zero heat flux at the lower boundary of the soil column. Soil thermal and hydraulic properties are calculated as a function of soil type. For the runoff, the model is divided into surface and base flow terms and includes parts from TOPMODEL (Stieglitz et al. 1997). The surface fluxes of momentum, sensible and latent heat are simulated using surface layer similarity theory.

Both BATS and CLM3.5 surface parametrization schemes were used in combination with Emanuel cumulus convection (Emanuel and Zivkovitch 1999) and these simulations were called, respectively, RegBATS and RegCLM. According to Reboita et al. (2014) and Llopart et al. (2014), the combination of the Emanuel and CLM3.5 schemes results in RegCM4 simulations that have smaller errors than those using other convective schemes over SA.

The simulations are for the 1979-2009 period, starting at 00:00 UTC January 1, with the first simulation year (1979) eliminated from the analysis to serve as the spin-up period. The atmospheric variables and sea surface temperature for simulations were provided by the Era-Interim reanalysis with horizontal grid spacing of $1.5^{\circ}$ (hereafter ERAIN; Dee et al. 2011). Figure 1 shows the simulation domain, which covers SA and adjacent oceans as suggested by CORDEX (Giorgi et al. 2009), with approximately 50-km horizontal grid spacing and 18 sigma-pressure levels.

\subsection{Datasets and validations}

\subsubsection{Gridded analysis}

For the RegCM4 evaluation, different observational datasets were used, due to the existence of uncertainties in the observed climatology over SA (da Rocha et al. 2014). For precipitation, four monthly gridded datasets were considered: Climate Prediction Center Merged Analysis of Precipitation (CMAP; Xie and Arkin 1997), Climate Research Unit of the University of East Anglia (CRU; Mitchell and Jones 2005), University of Delaware (UDEL; Legates and Willmott 1990) and Climate Prediction Center (CPC; Silva et al. 2007). CMAP merges information from different sources (rain gauges and satellite-based estimates) and it is available over the whole globe at $2.5^{\circ} \times 2.5^{\circ}$ resolution from 1979 to the present over both land and ocean. Monthly mean values of CRU and UDEL were obtained using only surface station observations and are available on a $0.5^{\circ} \times 0.5^{\circ}$ grid, up to 2014 . The $\mathrm{CPC}$ analysis is based on rain gauges only and has $0.5^{\circ} \times 0.5^{\circ}$ horizontal resolution from 1948 to 2014. CRU, UDEL and CPC datasets are available globally but only over land. Both UDEL and CRU were also used to validate the simulated air temperature. The simulated mass divergence and wind fields at $850 \mathrm{hPa}$ were compared with the ERAIN reanalysis from ECMWF with horizontal resolution of $0.75^{\circ} \times 0.75^{\circ}$ (Dee et al. 2011).

\subsubsection{Local observations: water and energy balance}

In order to understand the impacts of the physical processes associated with the BATS and CLM3.5 schemes in the simulated climatology, the water and energy balances were analyzed. The water balance was calculated according to:

Precip $=$ ET + Run + WS + WZ

where Precip is the precipitation, ET is the evapotranspiration, Run is the runoff, WS and WZ are, respectively, the soil water content in the surface and root zone layers. In order to make a direct comparison of soil moisture between the simulations, the soil moisture in both simulations is obtained according to the methodology proposed by Steiner et al. (2009), i.e., we converted the 10 CLM3.5 layers into each of three BATS soil layers. The BATS surface layer corresponds to the first three layers of CLM3.5 and in the CLM3.5 the water in the first eight to nine soil layers,
Fig. 1 a South America simulation domain, topography (m, shaded with scale at right) and the location of the sub-domain over the Amazon Basin (black inner square). $\mathbf{b}$ Location of flux tower measurements in Amazon Basin (dots)
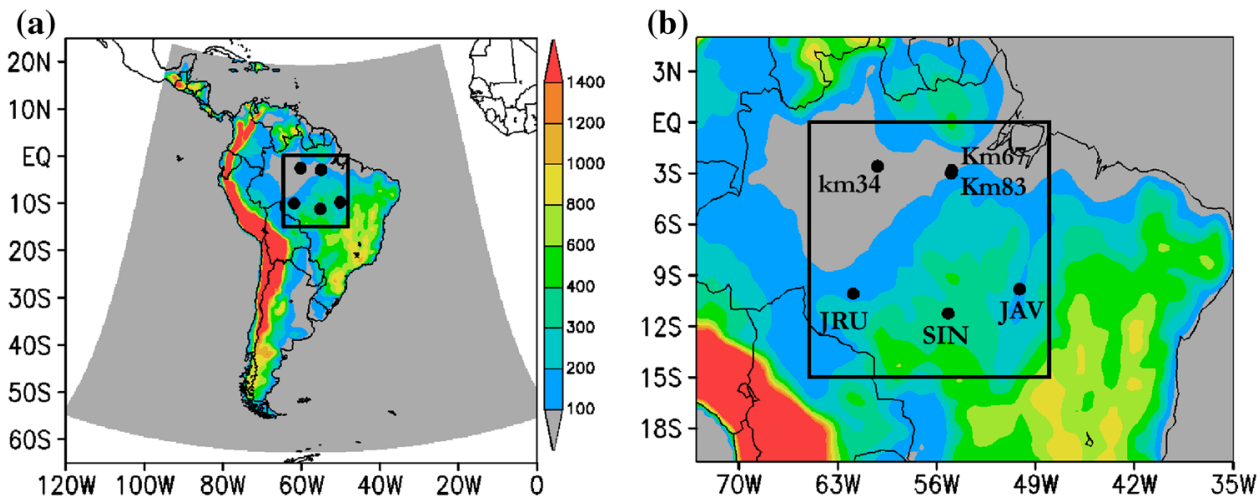
depending on the land cover type, provides the root zone soil moisture. For BATS the root zone moisture is given as the water in a single layer (the root zone layer) with different depths according to the land use type.

The energy budget at surface determines the amount of energy available to evaporate the surface water and to raise or lower the temperature (Hartmann 1994). The surface energy balance can be defined as:

$\mathrm{RN}=\mathrm{H}+\mathrm{LE}+\mathrm{G}$

$\mathrm{RN}$ being the net radiation, which was calculated from model outputs as the difference between SW (net short wave) and LW (net long wave); $H$ the sensible heat flux; LE the latent heat flux; and $G$ is the heat storage at surface. The Bowen ratio (Hartmann 1994) is defined as:

$B=\mathrm{H} / \mathrm{LE}$

The simulated annual cycles of the surface energy and water budgets over the Amazon region (see Fig. 1) were compared with the mean values at six micrometeorological flux observation towers (shown in Fig. 1b) from the LargeScale Biosphere-Atmosphere Experiment in Amazonia (LBA, da Rocha et al. 2009). More details about quality control, available periods and the annual cycle for each tower of the LBA dataset can be found in da Rocha et al. (2009). From the LBA tower, the analyzed variables were: evapotranspiration, sensible and latent heat flux, net radiation, and Bowen ratio. The annual cycles of the precipitation and air temperature over the AMZ were calculated as the average of the observed datasets (CMAP, CRU, UDEL and CPC for rainfall; UDEL and CRU for temperature).

\subsubsection{Interannual variability}

The climate variability over the Amazon basin is greatly influenced by events in remote regions. For example, the El Niño - Southern Oscillation (ENSO) influences the convection over the Amazon Basin, providing negative anomalies of rainfall over the central-western part of the basin during El Niño years (Grimm and Ambrizzi 2009). In the present work, the response of the land surface models coupled into RegCM4 to the interannual variability is analyzed by filtering the monthly anomalies of the near-surface variables (precipitation, air temperature, evapotranspiration, sensible heat flux, soil moisture and runoff) using the Fast Fourier Transform (FFT; Wilks 1995). The observed and modeled data were filtered on an interannual scale (more than 365 days) and the ENSO years were identified using the Oceanic Niño Index provided by NCEP/NOAA (ONI; http:// www.cpc.ncep.noaa.gov/products/analysis_monitoring/ ensostuff/ensoyears.shtml). This kind of analysis allows the assessment of whether or not the simulations capture the ENSO signal and also the identification of the influences of the surface processes on the modeled interannual anomalies of atmospheric variables.

\section{Results}

\subsection{Validation of the simulated climatology}

Figure 2 presents the annual climatology of precipitation, mass divergence and low level circulation at $850 \mathrm{hPa}$ observed and simulated by RegCLM and RegBATS. At an annual scale, the areas of most intense rainfall are observed in the Intertropical Convergence Zone (ITCZ) in both Atlantic and Pacific Tropical Oceans, from central Brazil to the north-northwestern Amazon basin and over southern Brazil and the adjacent Atlantic Ocean (Fig. 2a). The rainfall is weak in the subtropics over the Pacific and Atlantic oceans, over the eastern part of northeast Brazil and south-central Argentina. Comparing simulations with observations, the general pattern of the observed annual rainfall is simulated by both RegCLM (Fig. 2c) and RegBATS (Fig. 2e). However, the simulations underestimate the intensity of the precipitation in the ITCZ over both the Atlantic and Pacific oceans (Fig. 2a), and overestimate it over northwestern SA. In this area RegBATS has larger positive bias than RegCLM. In both simulations, over northwestern SA the overestimation of rainfall can be associated with the stronger simulated low level wind convergence over the region (Fig. $2 \mathrm{~b}-\mathrm{d}-\mathrm{f}$ ) and also due to the proximity of the steeper Andes Mountain, favoring intense upward motion and convection (da Rocha et al. 2009).

Comparing RegCLM and RegBATS large differences are noted in the precipitation intensity, mainly over tropical SA, induced by the use of different surface parameterization schemes (Fig. 2). The precipitation bias will be discussed in Sect. 3.2 through an analysis of the simulated surface fluxes.

In Fig. 2, the underestimation of the precipitation over La Plata Basin (southern Brazil, Uruguay and northeastern Argentina) by RegCLM and RegBATS is a common error in many RCMs (Solman et al. 2013; Menendez et al. 2010; Reboita et al. 2014; Llopart et al. 2014) and it is attributed to a set of factors. Some authors have associated this precipitation deficit with the surface specifications in the model (Solman et al. 2013), the convective parameterization scheme (Reboita et al. 2014), a weaker-than-observed low level jet east of the Andes Mountains (Fernandez et al. 2006a), differences in the frequency and intensity of cyclones (Reboita et al. 2010) and cold fronts (Jesus et al. 2016).

Regarding the air temperature (Fig. 3), RegCLM and RegBATS show two common biases: they are warmer and colder than observations over most of north-central and 
Fig. 2 Left column: annual climatology (1980-2009) of precipitation $\left(\mathrm{mm} \mathrm{day}^{-1}\right)$ from: a observation (mean value of CMAP, CRU, UDEL and CPC), c RegCLM and e RegBATS. Right column wind vectors (scale at the bottom) and divergence $\left(\times 10^{-5} \mathrm{~s}^{-1}\right.$, shaded with scale at the right) at $850 \mathrm{hPa}$ from: b ERAIN, d RegCLM and $\mathbf{f}$ RegBATS (a)

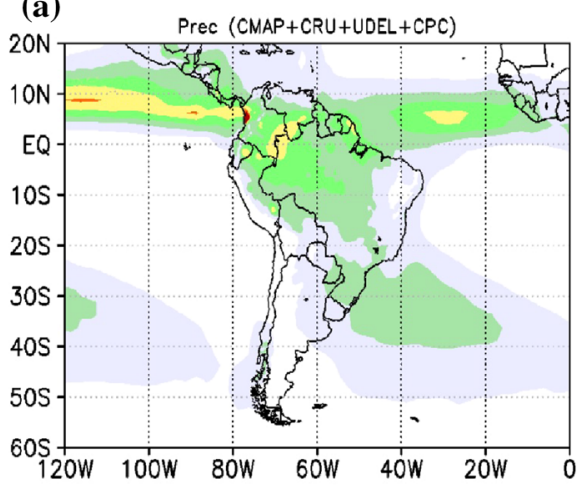

(b)

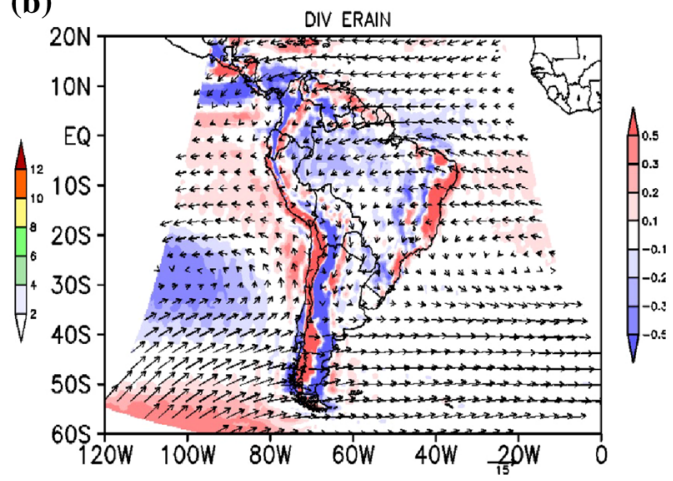

(c)

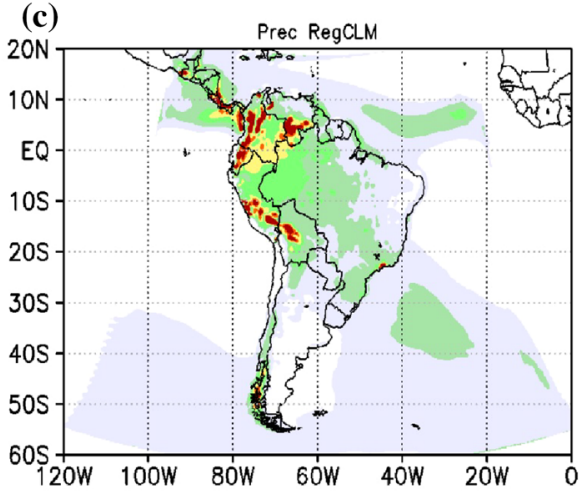

(d)

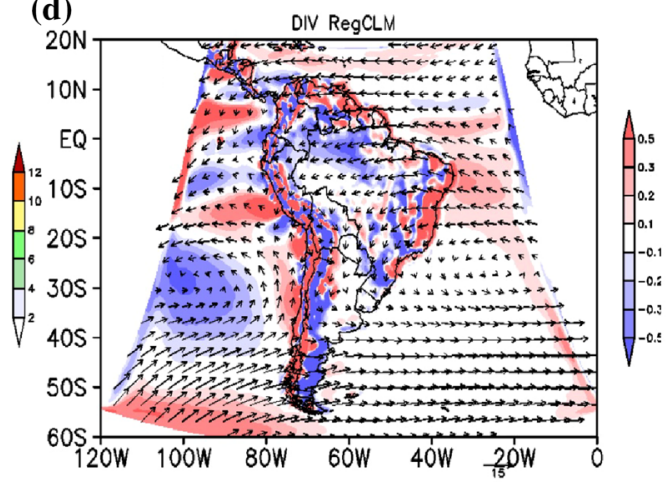

(e)

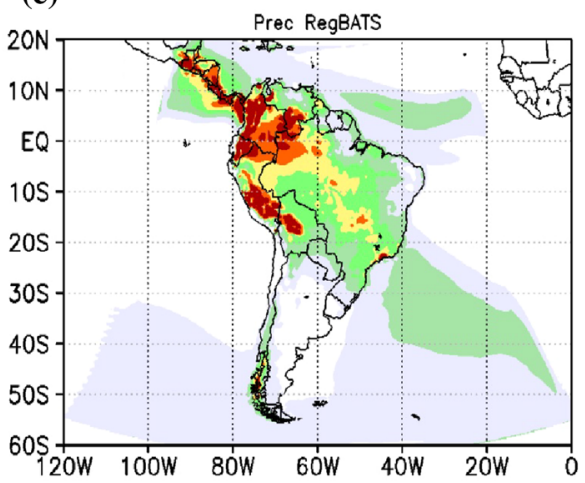

(f)

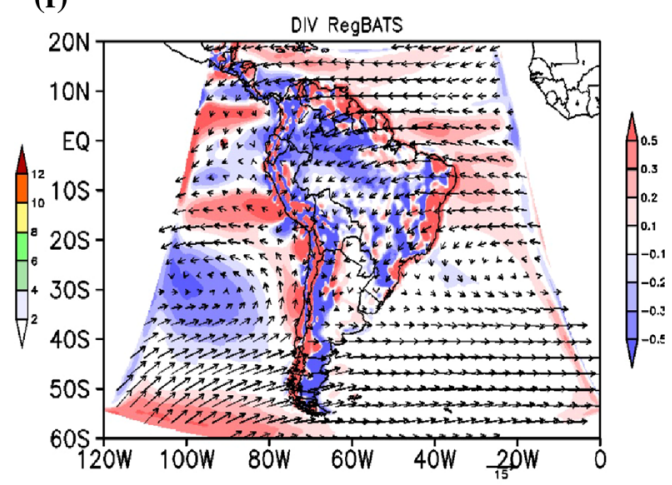

south-central SA, respectively. Over north-central SA, the RegCLM warm bias is smaller than in RegBATS, while in southern and southeastern Brazil RegCLM cold bias is greater than in RegBATS. Even though presenting a positive bias, in the RegCLM (Fig. 3a) the area and values of the warm bias over northeastern Argentina are smaller than in RegBATS (Fig. 3b). It is interesting to note that even with RegBATS simulating higher precipitation amounts (Fig. 2b) over the central-western Amazon it presents larger warm bias than RegCLM. Figure 3c also reveals that RegBATS simulates higher temperatures than RegCLM in most of SA, except over the Andes Mountain and south-central Argentina.

Figure $3 \mathrm{a}, \mathrm{b}$ show a positive bias of about $4{ }^{\circ} \mathrm{C}$ on the west coast of SA, from $10^{\circ}-30^{\circ} \mathrm{S}$. This occurs mostly due to underestimation in $\mathrm{RegCM}$ of the stratocumulus cloud cover in this area (Pessacg et al. 2013). The stratocumulus cloud cover over the west coast of SA is important in reducing the incidence of solar energy and thus preventing the occurrence of high air temperature. The stratocumulus cloud sheet occurs associated with the South Pacific subtropical anticyclone, and its absence is a common error in many global (Collins et al. 2006b) and regional (Pessacg et al. 2013) climate models.

\subsection{Water and energy balance}

The components of the surface water balance - precipitation (Precip), evapotranspiration (ET), runoff and the surface 
Fig. 3 Difference between the simulations and the observed (CRU + UDEL) air temperature $\left({ }^{\circ} \mathrm{C}\right)$ and between the two simulations: a RegCLM-OBS, b RegBATS-OBS, c RegBATSRegCLM
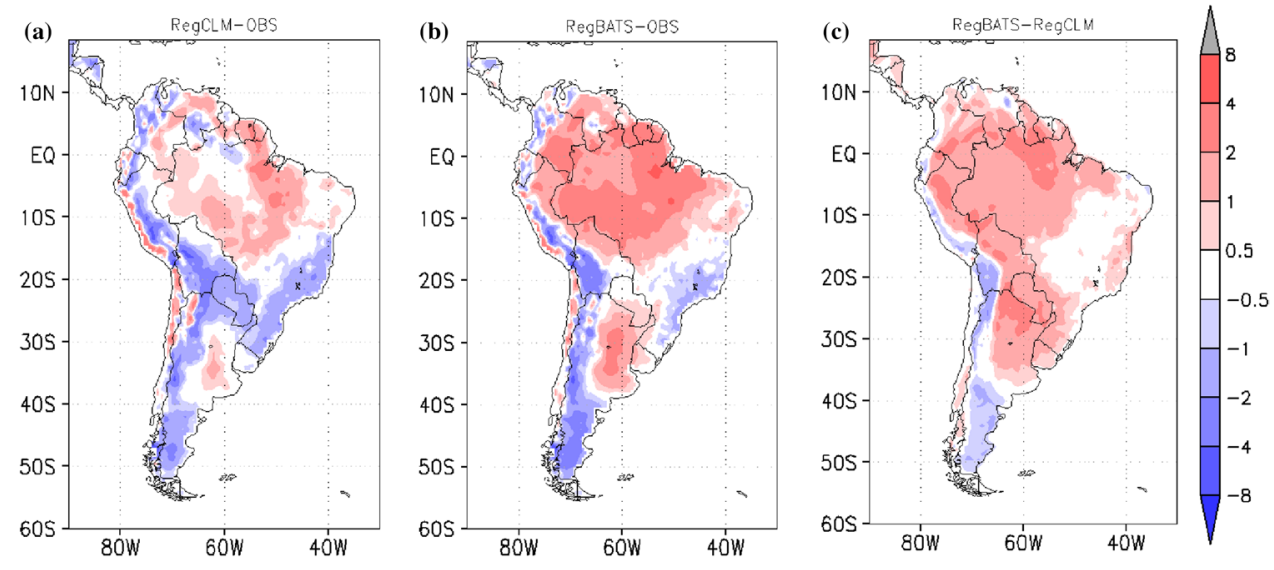

and root zone soil water-computed for $\mathrm{AMZ}$ region are presented in Fig. 4. The annual cycle of the observed precipitation corresponds to the average value of four datasets (CMAP, CPC, UDEL and CRU), the annual cycle of evapotranspiration represents the mean values of the LBA micrometeorological stations, while for the other variables only simulated values are presented.

Over AMZ, the observations show a well-defined annual cycle with large amounts of precipitation from October to May and smaller values from June to September (Fig. 4a). Both simulations capture properly the observed phase of the annual cycle of rainfall, with RegCLM presenting better agreement with observations than does RegBATS over most of the year. In both simulations the convective scheme is the main mechanism contributing to total rainfall (dashed line in Fig. 4a), with the convection normally occurring over tropical areas when the Emanuel scheme is used in RegCM4 simulations (da Rocha et al. 2016).

The mean annual cycle of ET observed in AMZ (Fig. 4b) shows small amplitude, with a small increase of ET values from July to October (dry season). During this period, there is observed a decrease of the cloud cover and an increase of solar radiation reaching the surface (da Rocha et al. 2009), mainly during the transition from the dry to the wet season, resulting in a small increase of the net radiation at the surface (see Fig. 5b). Some observational studies have shown that throughout the dry season ET is not often limited by the soil moisture (Saleska et al. 2007; da Rocha et al. 2004), probably due to deep root systems (e.g., Nepstad et al. 1994) that would sustain the ET increase at the end of the dry season (Fig. 4b). The simulated annual cycle of ET has a higher amplitude than that observed and it is in phase with the annual cycle of rainfall (Fig. 4a) presenting large (small) values during the wet (dry) months of the year (Fig. 4b). Compared to observations, there is a larger ET overestimation in RegBATS than in RegCLM during the rainy season. For July-August (which is part of dry season) RegCLM simulates ET values similar to the observations and RegBATS underestimates them. Since both RegCLM and RegBATS simulate an annual cycle of ET with phase different from that observed, they do not exhibit the observed increase of ET at the end of the dry season. This observed feature is also difficult to simulate in land surface models running in the off-line mode (de Gonçalves et al. 2013).

Figure $4 \mathrm{~b}$ indicates that RegCLM simulates ET values closer to the observations for July-August, while RegBATS underestimates it. In this same period, the rainfall rate simulated by RegBATS is similar to that observed (Fig. 4a), indicating that the moisture for convective activity is being supplied by mechanisms other than local evapotranspiration. From September to June, RegCLM and RegBATS overestimate the observed values of ET, but the overestimations are smaller in RegCLM, contributing to better agreement with the observations in RegCLM (Fig. 4a). In Fig. 5a-c from September-June, RegBATS overestimates the sensible heat flux $(H)$ and air temperature. This likely produced the deeper boundary layer (PBL) found in RegBATS (Fig. 4f) and, consequently, convection may be activated more frequently (Fig. 4a, dotted lines) in a moister environment (Fig. 4b), resulting in a large overestimate of rainfall by RegBATS (Fig. 4a). During the months that PBL height is almost the same in the two simulations (April, October and November), there is larger moisture flux convergence (green line in Fig. 4f) in RegBATS, which can explain its higher rainfall rates.

In every month of the year, the soil moisture at the surface and in the root zone simulated by RegBATS exceeds that of RegCLM (Fig. 4c, d). Steiner et al. (2009) attributed these differences between BATS and CLM in the simulated soil moisture to the use of varying soil boundary conditions. They conducted sensitivity tests implementing the CLM soil texture dataset in the BATS, resulting in a soil moisture 5-20\% drier than found using the BATS default dataset. However, the large availability of moisture in the soil is not sufficient for RegBATS to simulate higher 

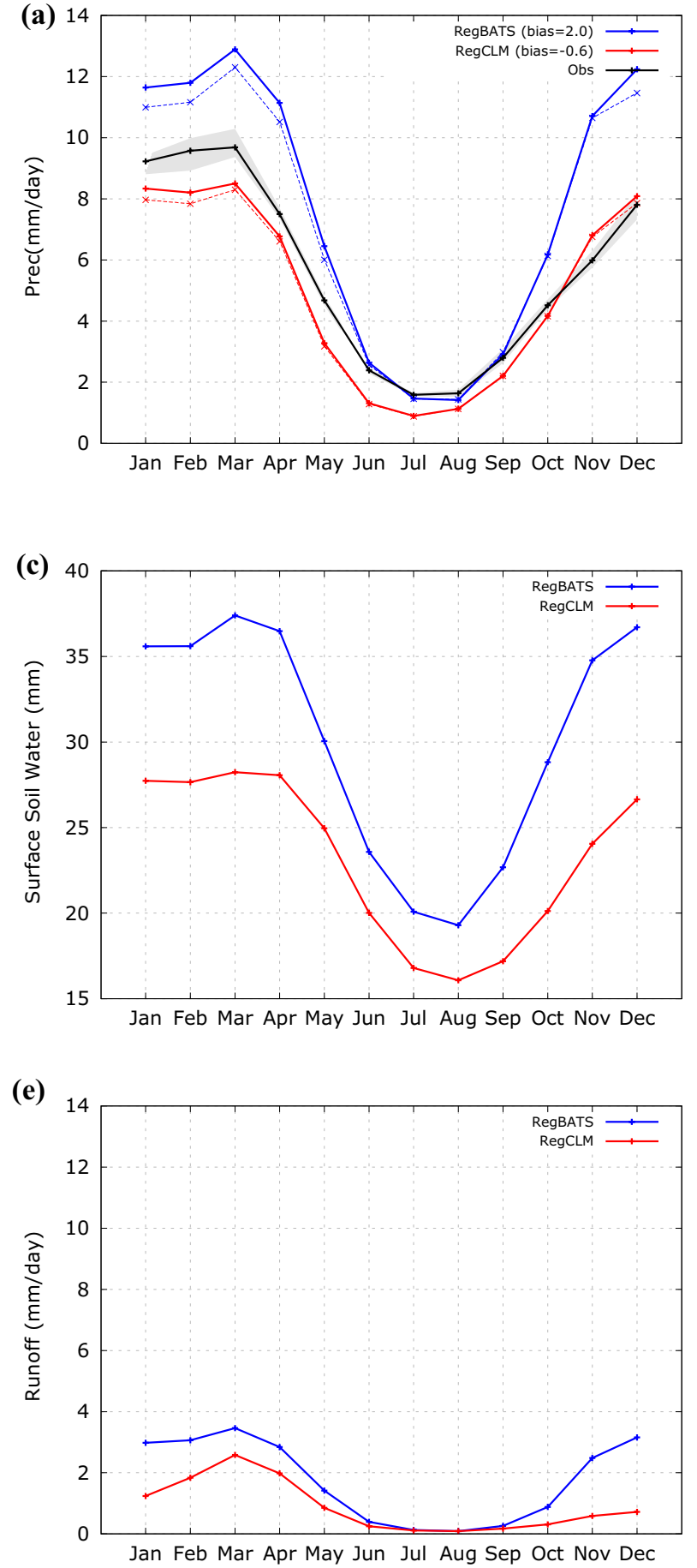

Fig. 4 Mean annual cycle computed in AMZ region using RegBATS (blue line), RegCLM (red line) and observation (black line; mean value using CRU, UDEL,CMAP,CPC for observed precipitation), crosses indicate the maximum and minimum observed values, for: a convective (dotted line) and total precipitation, both in $\mathrm{mm} \mathrm{day}^{-1}, \mathbf{b}$ evapotranspiration $\left(\mathrm{mm} \mathrm{day}^{-1}\right)$ (tower flux observation is shown as

ET rates than RegCLM during the dry season, indicating some deficiency of the root system in the BATS scheme. As discussed by da Rocha et al. (2012) the values of water
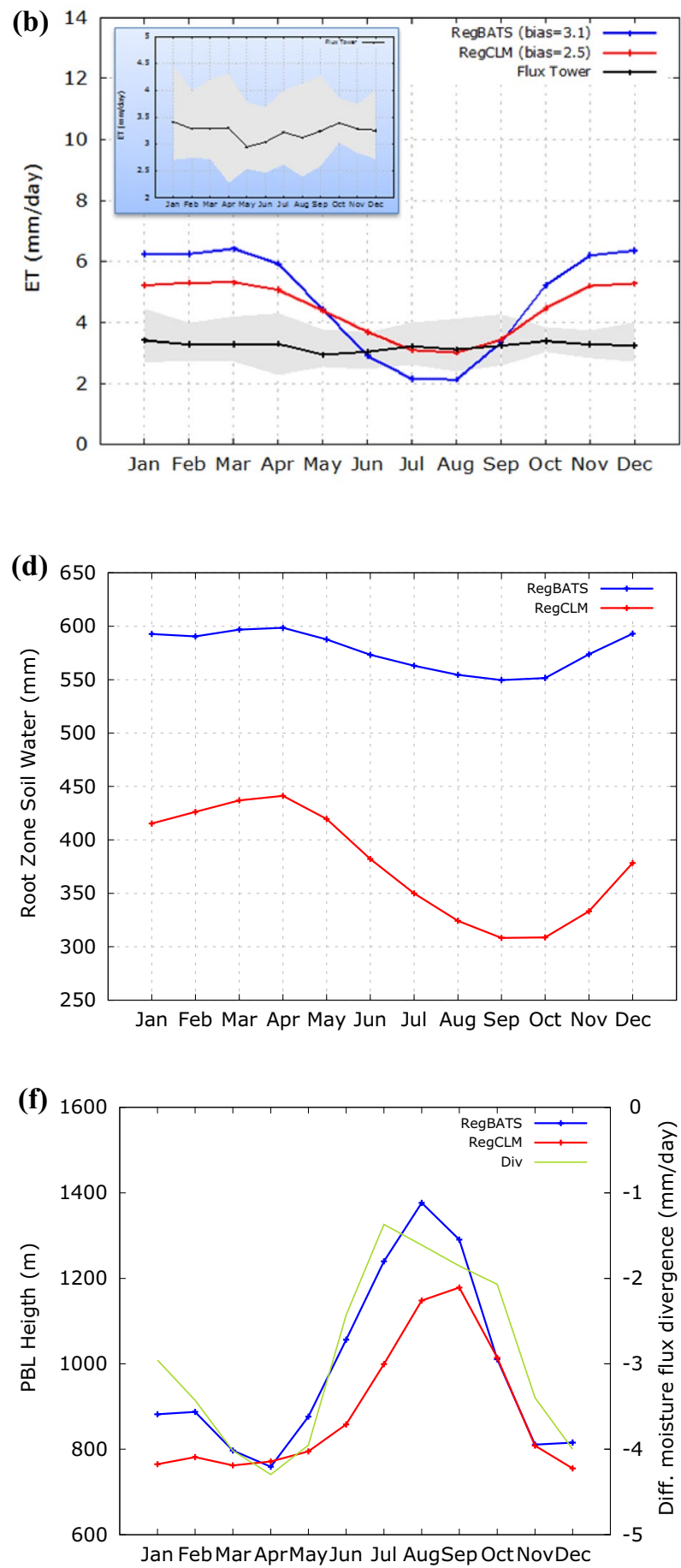

inset to highlight the observed annual cycle) $\mathbf{c}$ soil moisture in the surface layer $(\mathrm{mm})$, d soil moisture in the root zone $(\mathrm{mm})$, e runoff $\left(\mathrm{mm} \mathrm{day}^{-1}\right), \mathbf{f}$ planetary boundary layer height $(\mathrm{m})$ and the difference of moisture flux divergence between the two simulation (RegBATS minus RegCLM; mm/day)

content in the root zone simulated by RegCM3 using BATS may have large amplitude (annual mean between $~ 600$ and $1100 \mathrm{~mm}$ ) as a function of rainfall rate, depth of the 

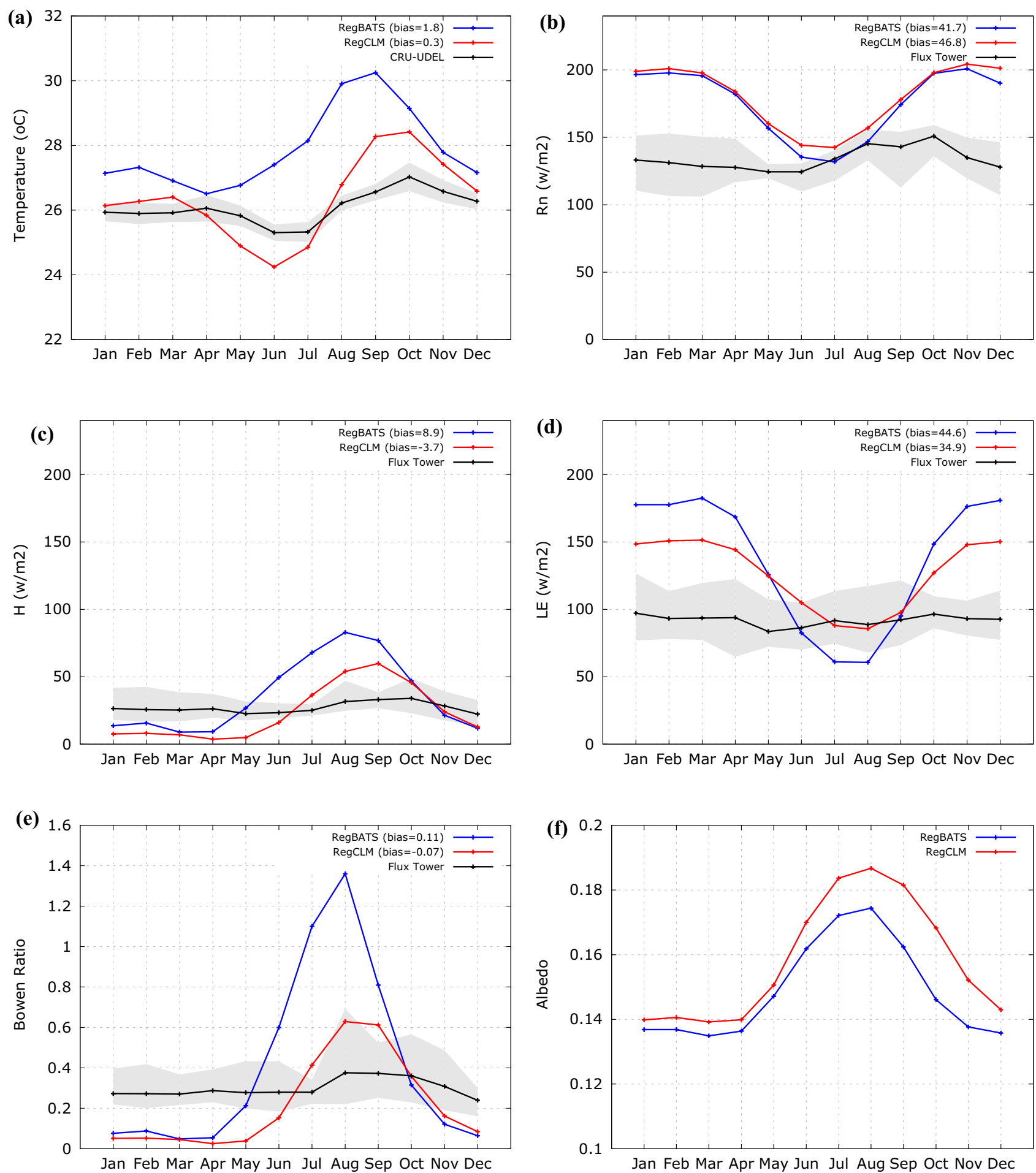

Fig. 5 Mean annual cycle of the surface energy balance over AMZ region simulated by RegBATS (blue line), RegCLM (red line) and observed (black line), cross indicate the maximum and mini-

mum observed values, for: $\mathbf{a}$ air temperature $\left({ }^{\circ} \mathrm{C}\right)$, b sensible heat flux $\left(\mathrm{W} \mathrm{m}^{-2}\right)$, c net radiance $\left(\mathrm{W} \mathrm{m}^{-2}\right)$, d latent heat flux $\left(\mathrm{W} \mathrm{m}^{-2}\right)$, e albedo and $\mathbf{f}$ Bowen ratio

root zone, hydraulic conductivity and ratio of root distribution between the upper soil and root zone soil layers. In terms of annual cycle, RegCLM soil moisture decreases in the dry season, in the surface layer as well as in the root

zone (Fig. 4c, d), presenting minimum values in the root zone (September-October) later than the minimum in the surface layer (July-August). Through in situ observations, Bruno et al. (2006) showed that in the Amazon region, soil 
moisture has strong seasonality, i.e., evident soil drying in shallow layers at the beginning of the dry season, followed by a drying in intermediate layers, and reaching a state near saturation during most of the rainy season. This pattern is evident in RegCLM with drying soil in the shallowest layer early in the dry season, followed by drying in the root zone soil layer, returning to higher moisture in the wet season. RegCLM also simulates a stronger annual amplitude of root zone soil moisture, meaning that the deeper soil layers in the CLM scheme can rapidly respond to changes in the upper layers.

RegBATS simulates larger runoff values than RegCLM for the period September-June (Fig. 4e), which is mainly a consequence of the large rainfall rate in RegBATS (Fig. 4a). In the other months, the two simulations have similar values of runoff. An interesting highlight is that the pattern of the annual cycle of runoff (Fig. 4d) agrees with that of precipitation (Fig. 4a).

For most of the year (excluding the period July-August), considering all surface water balance terms in Fig. 4, RegBATS simulates higher values than RegCLM of soil moisture, evapotranspiration, and consequently, precipitation and surface runoff.

Figure 5 presents the mean annual cycle of the surface energy balance components (sensible heat flux, $H$; net radiation, RN; latent heat flux-LE; and Bowen ratio) for the AMZ region. The mean annual cycle of observed temperature is taken as the average of the UDEL and CRU datasets. The annual cycle of air temperature simulated by RegCLM is closer to the observations, mainly during the dry season (Fig. 5a). During this period, the RegBATS overestimation of observed air temperature reaches up to $4{ }^{\circ} \mathrm{C}$, which may be explained, at least in part, by the strong increase of the sensible heat flux and decrease of the latent heat flux (Fig. 5c, d).

The lower albedo simulated by RegBATS allows greater absorption of solar energy by the surface (Fig. 5f). As a result, the RegBATS simulates larger values of the sensible heat flux $(H)$, explaining the high warm biases throughout most of the year (Fig. 5a). On the other hand, in RegBATS the latent heat flux is lower than RegCLM (Fig. 5d), a necessary condition for the closure of the energy balance, which is confirmed by similar values of the net radiation in the two simulations (Fig. 5b). The Bowen ratio is higher in RegBATS than in RegCLM during the dry season (Fig. 5e), indicating that most of the available energy is being used to heat the air and little for evapotranspiration in the RegBATS. The observed Bowen ratio is almost constant throughout the year, and RegCLM simulates this feature better than RegBATS (Fig. 5e). Therefore, RegCLM simulates a more realistic energy partition with a consequent reduction of errors in the simulation of the annual cycles of precipitation and air temperature. But even with RegCLM simulating surface fluxes nearer to those observed than RegBATS does, some deficiency in representing the magnitude and phase of the observations is noted. This indicates the need of further improvements in the CLM and associated Emanuel schemes coupled in RegCM, to obtain more realistic representation of surface processes.

\subsection{Interannual variability}

For the AMZ region, Fig. 6 presents the monthly values of the precipitation and air temperature anomalies on an interannual scale. These series were obtained by applying to the total monthly anomalies a time filter that retains only the interanual scale (greater than 365 days). For precipitation, the simulated signal of interannual anomalies is similar to $\mathrm{CRU}$, as reflected in the high values of time correlation between CRU and simulations of 0.77 and 0.73 for RegBATS and RegCLM, respectively. However, from Fig. 6a it is clear that the simulated values on the interannual scale are, in general, stronger than CRU. Simulated patterns of the rainfall anomalies in RegBATS and RegCLM are also very similar (time correlation of 0.94), but with different intensities. A general rule is that RegBATS simulates higher anomalies, both negative and positive. This provides more intense precipitation amounts on the interannual scale in RegBATS than in RegCLM and CRU.

The simulated interannual signals of the air temperature are similar to those of CRU (Fig. 6b). However, both RegBATS and RegCLM amplify the intensity of the anomaly;
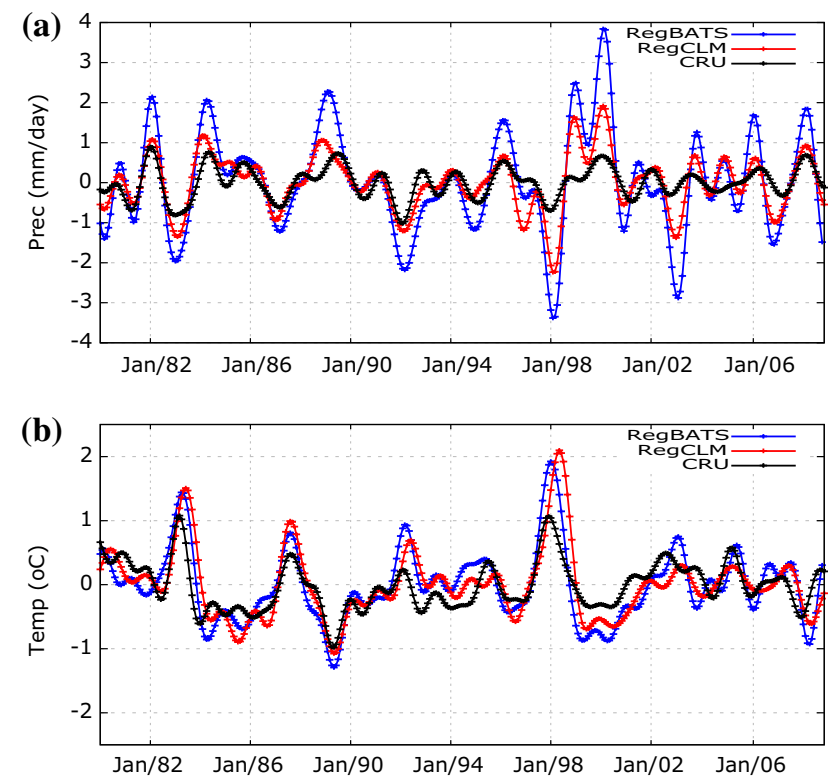

Fig. 6 Time series of montlhy anomalies on an interannual scale (>365 days) over AMZ from CRU (black line), RegBATS (blue line) and RegCLM (red line) for: a precipitation $\left(\mathrm{mm} \mathrm{day}^{-1}\right)$ and $\mathbf{b}$ air temperature $\left({ }^{\circ} \mathrm{C}\right)$ 
in particular, RegBATS simulates a stronger than observed interannual variability of air temperature. One interesting point in Fig. 6b is that in some events the simulated anomalies are out of phase compared with CRU. For example, during the El-Niño of 1997-1998 the maximum positive anomaly of air temperature occurs in December,1997 in CRU, January,1998 in RegBATS and May,1998 in RegCLM, i.e., there is a delay of five (one) months in RegCLM (RegBATS) compared with CRU. In another positive event, that of August 1987, the two simulations are in phase with CRU (Fig. 6b). For a time lag of zero, the time correlation between the series of air temperature anomaly is 0.77 for RegBATS versus CRU and 0.69 for RegCLM versus CRU, indicating a larger difference of phase between RegCLM and CRU. The larger correlation of 0.78 occurs for a time lag of 1 month between CRU and RegBATS and of 0.79 with a 4-month time lag between CRU and RegCLM, i.e., there is a longer delay in the peaks of the temperature signal in RegCLM.

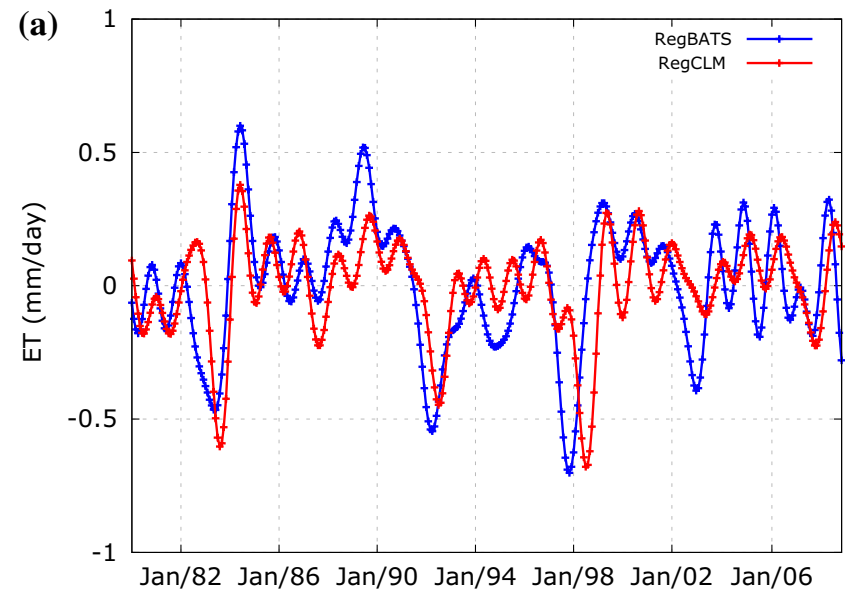

(c)

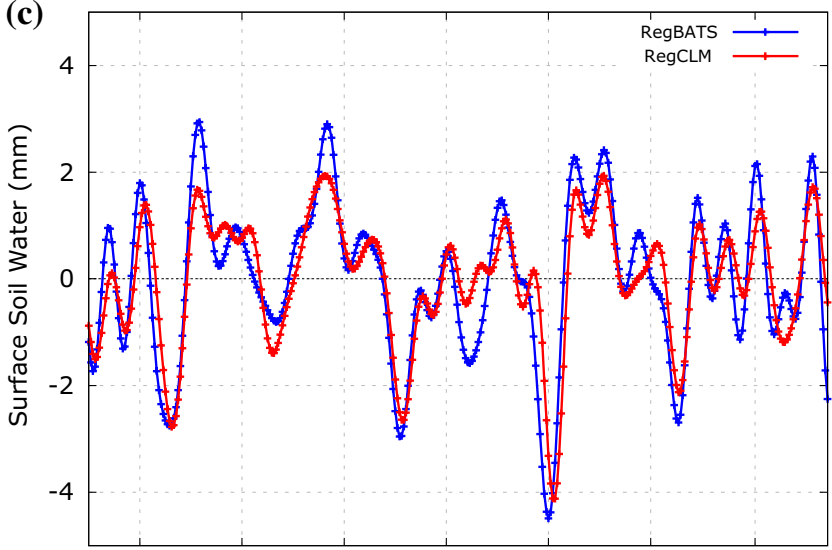

Jan/82 Jan/86 Jan/90 Jan/94 Jan/98 Jan/02 Jan/06
Figure 7 depicts the time series of the terms in the surface water budget of the simulated monthly anomalies filtered on an interannual scale. The variables evapotranspiration, surface layer soil moisture, and runoff are out of phase according Fig. $7 \mathrm{a}-\mathrm{c}$, respectively. Considering the 1997-1998 El Niño event the RegCLM simulated negative anomalies of these variables are delayed compared with RegBATS. As mentioned before, El Niño years are associated with negative anomalies of rainfall over the east-central Amazon Basin (Ropelewski and Halpert 1987, 1989; Marengo 1992; Uvo 1998), which in turn causes a decrease in soil moisture after a certain period (the soil memory timescale is on the order of about 1-2 months in the Amazon basin; Koster and Suarez 2001; Bruno et al. 2006; Seneviratne et al. 2006; Dirmeyer et al. 2009b; Orlowsky and Seneviratne 2010; Koster et al. 2004). After the soil moisture decreases, there is a reduction of the evapotranspiration and runoff. This temporal evolution of the water budget variables was simulated by RegCLM (Fig. 7), with
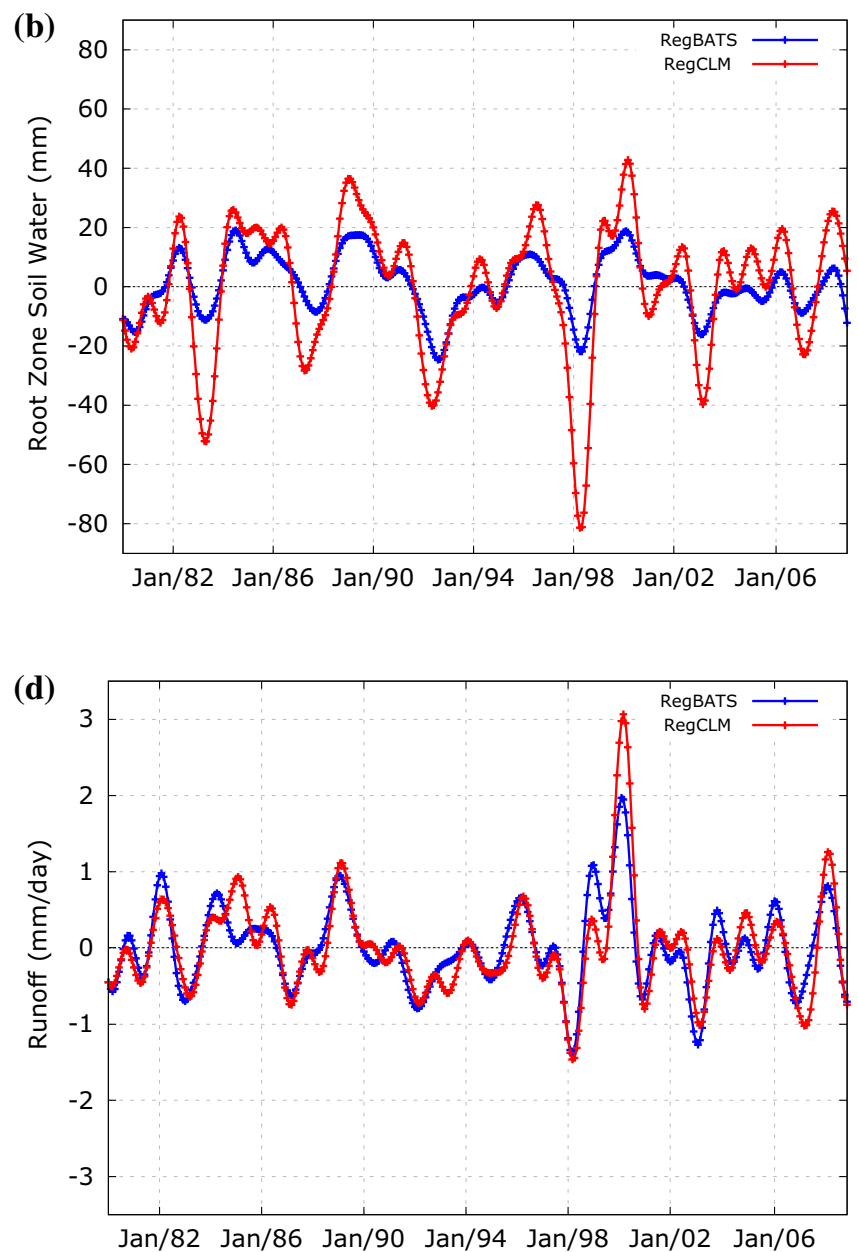

Fig. 7 Time series of montlhy anomalies on an interannual scale ( $>365$ days) over AMZ from RegBATS (blue line) and RegCLM (red line) for: a evapotranspiration $\left(\mathrm{mm} \mathrm{day}^{-1}\right), \mathbf{b}$ root zone soil water $(\mathrm{mm}), \mathbf{c}$ surface soil water $(\mathrm{mm})$ and $\mathbf{d}$ runoff $\left(\mathrm{mm} \mathrm{day}^{-1}\right)$ 
a delay of 2 months in the depletion of the evapotranspiration and soil moisture during the 1997-1998 El Niño event. For RegBATS, only in the root zone layer is there any soil moisture memory (Fig. 7b), while in the surface layer the soil moisture anomaly is in phase with the anomaly of precipitation. As a consequence, in RegBATS during the 1997-1998 El Niño event the decrease of rainfall immediately impacts the soil moisture in the first layer, resulting in a negative anomaly of evapotranspiration and runoff (Fig. 7).

The interannual anomalies of sensible heat simulated by RegCLM and RegBATS are in general out of phase (Fig. 8). For example, for the year 1998 in RegCLM there is a decrease of evapotranspiration after the decrease of the rainfall and water content in the root zone (Fig. 8). Thus, the positive anomaly of sensible heat in the RegCLM only increases after intensification of the negative anomaly of evapotranspiration, i.e., the maximum positive anomaly of $\mathrm{H}$ occurs four months after the minimum negative anomaly of rainfall in 1998. This occurs as a result of the energy budget closure: the decrease (increase) in evapotranspiration increases (decreases) the sensible heat flux. On the other hand, the RegBATS presents a simultaneous response of the evapotranspiration, i.e., at the same time that the negative precipitation anomaly is increasing there is an increase of the $\mathrm{H}$ anomaly. Since the RegCLM delays the increase of the positive anomaly of sensible heat, it is only possible to notice the increase in positive anomaly of the air temperature 2-4 months after the observed increase (Fig. 6b). On the other hand, RegBATS is already in phase with the observed air temperature anomalies.

\section{Conclusions}

The present work evaluated the impacts of two land surface schemes coupled in the RegCM4 model upon the simulated climatology and its variability over the South American CORDEX domain. For the period from 1979 to 2008,

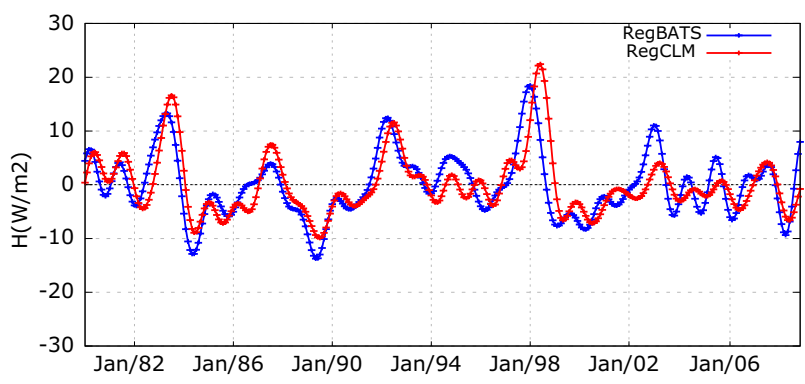

Fig. 8 Time series of montlhy anomalies on an interannual scale (>365 days) over AMZ from RegBATS (blue line) and RegCLM (red line) for sensible heat flux $\left(\mathrm{W} \mathrm{m}^{-2}\right)$ two RegCM4 experiments using the ERA-Interim reanalysis as initial and boundary conditions were compared: one with the BATS (RegBATS) and the other with the CLM3.5 (RegCLM) land surface schemes.

The simulations indicate important differences in both climatology and climate variability as functions of the surface scheme. In the period 1980-2008, for the rainfall climatology there is a strong wet bias in RegBATS over most of South America. For RegCLM the rainfall rate is in general smaller than in RegBATS, resulting in lower biases in RegCLM. For north-central South America, the more intense mass convergence at $850 \mathrm{hPa}$ and large evaporation rate contribute to intensifying the precipitation and explain, at least in part, the large wet bias in RegBATS. The simulation biases in air temperature climatology are also smaller in RegCLM than in RegBATS.

For the Amazon basin, the simulated annual cycles of rainfall are in phase with the observations, i.e., with the rainy and dry seasons occurring, respectively, from October-April and May-September. For the rainy season, RegCLM simulates rainfall intensities similar to those observed, while RegBATS is wetter. The smaller evapotranspiration rate, together with lower values of mass convergence, help to explain the low rainfall in RegCLM during the rainy season. For the dry season, there is an inversion of this pattern, i.e., both rainfall and evapotranspiration rates are lower in RegBATS, which result in a small bias in RegBATS. For the year as a whole, in both simulations the air temperatures are higher than observed, with larger overestimation during the dry season. The simulated warm bias over the Amazon is larger in RegBATS than RegCLM, especially during the dry season. This is linked to the lower albedo values in RegBATS, particularly during the dry season, providing greater absorption of solar energy by the surface with consequent increase in the sensible heat flux, resulting in higher air temperature (larger warm bias in RegBATS). RegCLM's smaller air temperature biases are the result of better similarity between the simulated and the observed (by the micrometeorological towers) energy partition. Overall, the monthly values of the terms in the water and energy balances at the surface simulated by RegCLM are closer to the observations.

Surface processes also impact the phase and intensity of the interannual variability signal over the Amazon basin. For precipitation, although both surface schemes show good agreement (with time correlation greater than 0.73 ) of phase between the simulated and observed interannual signal, higher amplitude is noted in RegBATS. The interannual anomalies of air temperature simulated by RegBATS have phase similar to the observed, while 2-4 months'delay occurs in RegCLM compared with observations. In the RegCLM, the impact on soil moisture (increase or decrease) occurs some time after the precipitation anomaly 
(increase or decrease), which is in accord with in situ observations (Bruno et al. 2006). As a direct consequence of changes in rainfall occurring first, the changes in soil moisture with impacts on the evapotranspiration rate and runoff are seen later on. The impacts on evapotranspiration occur in accord with the soil memory timescale (2-4 months) and the sensible heat and air temperature will change (increase/ decrease) after the change in the evapotranspiration. This mechanism explains the delay with respect to the observation of interannual anomalies of air temperature in RegCLM. On the other hand, in RegBATS the changes of soil moisture, evapotranspiration and runoff are simultaneous, i.e., occur at same time as the change in the rainfall due to some large scale forcing. Therefore, in RegBATS the interannual signal of sensible heat flux and air temperature is in phase with changes in the precipitation. Even while simulating higher amplitude of the interannual anomalies compared with observations, RegBATS still simulates the phase of these anomalies better than RegCLM.

In sumary some improvement in the simulated climatology, energy and water budgets and intensity of the interannual anomaly occur with the use of a more physically consistent CLM surface scheme. However, the CLM still encounters some difficulties in reproducing the observed phase of the interannual variability as well as the surface energy budget, which may be a result of the association of the CLM with the Emanuel convective scheme in RegCM4. This will be the subject of future investigations.

Acknowledgments The authors would like to acknowledge financial support from Conselho Nacional de Desenvolvimento Científico e Tecnológico (CNPq) - Brazil (Procs. 155700/2010-3, 249244/20136, 474929/2013-2, 474881/2013-0 and 307547/2014-0), and from Fapesp GoAmazon (Proc.2013/50521-7) and CAPES/PROEX. We thank the reviewers for their constructive and helpful comments and suggestions.

\section{References}

Bonan GB (1996) A land surface model (LSM version1) for ecological, hydrological, and atmospheric studies: technical description and user's guide. NCAR Technical Note NCAR/TN-417 + STR. National Center for Atmospheric Research, Boulder, CO, p 150

Bruno RD, da Rocha HR, de Freitas HC, Goulden ML, Miller SD (2006) Soil moisture dynamics in an eastern Amazonian tropical forest. Hydrol Processes 20:2477-2489

Collins WD, Lee-Taylor JM, Edwards DP, Francis GL (2006b) Effects of increased near-infrared absorption by water vapor on the climate system. J. Geophys. Res., in press

da Rocha HR, Goulden ML, Miller S, Menton MC, Oliveira Pinto LDV, Freitas H, Figueira AMS (2004) Seasonality of water and heat fluxes over a tropical Forest in eastern Amazônia. Ecological Applications, S22-S32

da Rocha HR, Manzi AO, Cabral OM, Miller SD, Goulden ML, Saleska SR, R.-Coupe N, Wofsy SC, Borma L et al (2009) Patterns of water and heat flux across a biome gradient from tropical forest to savanna in Brazil. J Geophys Res 114:G00B12. doi:10.1 029/2007JG000640

da Rocha RP, Cuadra SV, Reboita MS, Kruger LF, Ambrizzi T, Krusche N (2012) Effects of RegCM3 parameterizations on simulated rainy season over South America. Clim Res 52:253-265

da Rocha RP, Reboita MS, Llopart M (2016) A comparative analysis of the horizontal resolution impacts in simulated climate over South America. http://indico.ictp.it/event/7613/session/2/contribution/18/material/slides/0.pdf

da Rocha RP, Reboita MS, Dutra LMM, Llopart M, Coppola E (2014) Climatic Change 125: 95. doi:10.1007/s10584-014-1119-y

Dai Y, Zeng QC (1997) A land surface model (IAP94) for climate studies. Part I: formulation and validation in off-line experiments. Adv Atmos Sci 14:433-460

de Gonçalves LGG, Borak JS, Costa MH, Saleska SR, Baker I et al (2013) Overview of the large-scale biosphere-atmosphere experiment in Amazonia Data Model Intercomparison Project (LBADMIP). Agric For Meteorol 182-183:111-127

de Jesus EM, da Rocha RP, Reboita MS, Llopart M, Mosso Dutra LM, Remedio ARC (2016) Contribution of cold fronts to seasonal rainfall in simulations over the southern La Plata Basin. Clim Res 68:243-255

Deardorff J (1978) Efficient prediction of ground surface temperature and moisture, with inclusion of a layer of vegetation. J Geophys Res 83:1889-1903

Dee DP et al (2011) The ERA-Interim reanalysis: configuration and performance of the data assimilation system. Q J R Meteorol Soc 137:553-597

Dickinson RE, Henderson-Sellers A, Kennedy PJ, Wilson MF (1993) Biosphere-Atmosphere Transfer Scheme (BATS) version 1e as coupled to Community Climate Model. NCAR Tech. Note NCAR/TN-387 + STR, p 72

Dirmeyer PA, Schlosser CA, Brubaker KL (2009b) Precipitation, recycling, and land memory: an integrated analysis. J Hydrometeorol 10(1):278-288. doi:10.1175/2008JHM1016.1

Elguindi N, Bi X, Giorgi F, Nagarajan B, Pal J, Solmon F (2004) RegCM version 3.0 user's guide. Trieste: PWCG Abdus Salam ICTP, p 48

Emanuel KA, Zivkovic-Rothman M (1999) Development and evaluation of a convection scheme for use in climate models. J Atmos Sci 56:1766-1782

Fernandez JPR, Franchito SH, Rao VB (2006a) Simulation of summer circulation over South America by two regional climate models. Part I. Mean climatology. Theor Appl Climatol 86:247-260

Giorgi F, Jones C, Asrar GR (2009) Addressing climate information needs at the regional level: The CORDEX framework. WMO Bull 58:175-183

Giorgi F, Coppola E, Solmon F et al (2012) RegCM4: Model description and preliminary tests over multiple CORDEX domains. Clim Res 52:7-29

Grimm AM, Ambrizzi T (2009) Teleconnections into South America from the tropics and extratropics on interannual and intraseasonal timescales. In: Past climate variability in South America and surrounding regions: from the last glacial maximum to the Holocene. In: Vimeux F, Sylvestre F, Khodri M (eds) Developments in paleoenvironmental research. Springer, Netherlands, pp 159-191, doi:10.1007/978-90-481-2672-9

Hartmann DL (1994) Global physical climatology. Academic Press, San Diego

Koster RD, Suarez MJ (2001) Soil moisture memory in climate models. J Hydrometeor 2:558-570

Koster RD et al (2004) Regions of strong coupling between soil moisture and precipitation. Science 305(5687):1138-1140

Koster R, Mahanama S, Yamada T, Balsamo G, Boisserie M, Dirmeyer P, Doblas-Reyes F, Gordon T, Guo Z, Jeong JH, Li Z, Luo L, Maleysev S, Merryfield W, Seneviratne SI, Stanelle 
T, van den Hurk B, Vitart F, Wood EF (2010) The contribution of land surface initialization to subseasonal forecast skill: first results from the GLACE-2 project. Geophys Res Lett 37:L02402

Koster RD, Mahama, a S, Yamada TJ, Balsamo G et al (2011) The second phase of the global land-atmosphere coupling experiment: Soil moisture contributions to subseasonal forecast skill. J Hydrometeorol 12:805-822

Legates DR, Willmott CJ (1990) Mean seasonal and spatial riability in gauge corrected, global precipitation. Int J Climatology 10:111-127

Llopart M, Coppola E, Giorgi F, da Rocha RP, Cuadra S. Climatic Change (2014) 125: 111. doi:10.1007/s10584-014-1140-1

Marengo J (1992) Interannual variability of surface climate in the Amazon basin. Int J Climatol 12:853-863

Menendez CG et al (2010) claris project: towards climate downscaling in South America. Meteorol Z 19:357-362

Misra V, Dirmeyer PA, Kirtman BP (2002) Regional simulation of interannual variability over South America. J Geophys Res 107:8036. doi:10.1029/2001JD900216

Mitchell TD, Jones PD (2005) An improved method of constructing a database of monthly climate observations and associated highresolution grids. Int J Climatology 25:693-712

Nepstad DC, Carvalho CR de, Davidson EA, Jipp PH, Lefebvre PA, Negreiros GH, Silva ED da, Stone TA, Trumbore SE, Vieira S (1994) The role of deep roots in the hydrological and carbon cycles of Amazonian forests and pastures. Nature 372:66-669

Oleson KW, Niu G, Yang ZL, Lawrence DM et al (2008) Improvements to the community land model and their impact on the hydrologic cycle. J Geophys Res 113:G01021. doi:10.1029/200 7JD000563

Orlowsky B, Seneviratne SI (2010) Statistical analyses of land atmosphere feedbacks and their possible pitfalls. J Clim 23:3918-3932

Pal JS et al (2007) Regional climate modeling for the developing world: the ICTP RegCM3 and RegCNET. Bull Am Meteorol Soc 88:1395-1409

Pessacg NL, Solman SA, Samuelsson P, Sanchez E, Marengo J, Li L, Remedio ARC, Rocha RPd, Mourão C, Jacob D (2013) The surface radiation budget over South America in a set of regional climate models from the CLARIS-LPB project. Clim Dyn. doi:10.1007/s00382-013-1916-4

Rauscher SA, Seth A, Liebmann B, Qian J-H, Camargo SJ (2007) Regional climate model-simulated timing and character of seasonal rains in South America. Mon Wea Rev 135:2642-2657.

Reboita MS, da Rocha RP, Ambrizzi T, Sugahara S (2010) South Atlantic Ocean cyclogenesis climatology simulated by regional climate model (RegCM3). Clim Dyn 35:1331-1347

Reboita MS, Fernandez JPR, Llopart MP, Rocha RP, Pampuch LA, Cruz FT (2014) Assessment of RegCM4.3 over the CORDEX South America domain: sensitivity analysis for physical parameterization schemes. Clim Res 60:215-234

Ronchail J, Cochonneau G, Molinier M, Guyot JL, Gorreti A, Guimarães V, de Oliveira E (2002) Interannual rainfall variability in the Amazon basin and sea surface temperatures in the equatorial Pacific and the tropical Atlantic Oceans. Int J Climatol 22:1663-1686

Ropelewski CF, Halpert MS (1987) Global and regional scale precipitation patterns associated with El Niño/Southern Oscillation. Mon Wea Rev 115:1606-1626

Ropelewski CF, Halpert MS (1989) Precipitation patterns associated with the high index phase of the Southern Oscillation. J Clim 2:268-284

Saleska SR, Didan K, Huete A, da Rocha HR (2007) Amazon forests green-up during 2005 drought. Science 318(5850):612

Sellers PJ, Shuttleworth WJ, Dorman J (1989) Calibrating the simple biosphere model for amazonian tropical forest using field and remote sensing data. Part I: Average calibration with field data. J Appl Meteorol 28:727-759

Sellers PJ, Randall DA, Collatz CJ, Berry JA, Field CB, Dazlich DA, Zhang C, Collelo GD (1996a) A revised land surface parameterization (SiB2) for atmospheric GCMs, Part I: Model formulation. J Climate 9:676-705

Sellers PJ, Dickinson RE, Randall DA, Betts AK, Hall FG, Berry JA, Collatz GJ, Denning AS, Mooney HA, Nobre CA, Sato N, Field CB, Henderson-Sellers A (1997) Modeling the exchanges of energy, water, and carbon between continents and the atmosphere. Science 275(5299):502-509

Seneviratne SI, Lüthi D, Litschi M, Schär C (2006) Land atmosphere coupling and climate change. Eur Nat 443:205-209

Seth A, Rauscher SA, Carmago SJ, Qian JH, Pal JS (2007) RegCM3 regional climatologies using reanalysis and ECHAM global model driving fields. Climate Dyn 28:461-480

Silva VBS, Kousky VE, Shi W, Higgins RW (2007) An improved historical daily precipitation analysis for Brazil. J Hydrometeorol 8:847-861

Silva MES, Pereira G, da Rocha RP (2015) Theor Appl Climatol 125:609. doi:10.1007/s00704-015-1516-9

Solman SA, Sanchez E, Samuelsson P, da Rocha RP, Li L, Marengo J, Pessacg NL, Remedio ARC, Chou SC, Berbery H, Le Treut H, de Castro M, Jacob D (2013) Evaluation of an ensemble of regional climate model simulations over South America driven by the ERA-Interim reanalysis: model performance and uncertainties. Clim Dyn 41(5-6):1139-1157

Sörensson AA, Menéndez CG (2011) Summer soil-precipitation coupling in South America. Tellus Ser A Dyn Meteorol Oceanogr 63:56-68

Sörensson AA, Menéndez CG, Samuelsson P, Willén U, Hansson U (2010) Soil-precipitation feedbacks during the South American Monsoon as simulated by a regional climate model. Clim Change 98:429-447

Steiner AL, Pal JS, Giorgi F, Dickinson RE, Chameides WL (2005) Coupling of the common land model (CLM0) to a regional climate model (RegCM). Theor Appl Climatol 82(3-4):225-243

Steiner AL, Pal JS, Rauscher SA, Bell JL et al (2009) Land surface coupling in regional climate simulations of the West Africa monsoon. Clim Dyn 33(6):869-892

Stieglitz M, Rind D, Famiglietti J, Rosenzweig C (1997) An efficient approach to modeling the topographic control surface hydrology for regional and global climate modeling. J Clim 10:118-137

Stocker TF, Qin D, Plattner GK, Tignor M, Allen SK, Boschung J et al (2013) IPCC 2013 Summary for Policymakers. In Climate Change 2013: The Physical Science Basis. Contribution of Working Group I to the Fifth Assessment Report of the Intergovernmental Panel on Climate Change. Cambridge University Press, Cambridge

Tawfik AB, Steiner AL (2011) The role of soil ice in land-atmosphere coupling over the United States: a soil moisture precipitation winter feedback mechanism. J Geophys Res 116:D02113

Torrence C, Compo GP (1998) A practical guide to wavelet analysis. Bull Amer Meteor Soc 79:61-78

Uvo CRB, Repelli CA, Zebiak S, Kushnir Y (1998) The relationship between tropical Pacific and Atlantic SST and northeast Brazil monthly precipitation. J Climate 11:551-562

Vera $\mathrm{C}$ et al (2006) Toward a unified view of the American monsoon systems. J Climate 19:4977-5000

Wilks DS (1995) Statistical Methods in the atmospheric sciences: an introduction. Academic Press, p 467

Xie P, Arkin PA (1997) Global precipitation: a 17-year monthly analysis based on gauge observations, satellite estimates, and numerical model outputs. Bull Amer Meteor Soc 78:2539-2558 